\title{
Vitamin D Fortification of Fluid Milk Products and Their Contribution to Vitamin D Intake and Vitamin D Status in Observational Studies-A Review
}

\author{
Suvi T. Itkonen * (iD), Maijaliisa Erkkola ${ }^{(\mathbb{D})}$ and Christel J. E. Lamberg-Allardt ${ }^{(1)}$ \\ Department of Food and Nutrition, P.O. Box 66, 00014 University of Helsinki, 00790 Helsinki, Finland; \\ maijaliisa.erkkola@helsinki.fi (M.E.); christel.lamberg-allardt@helsinki.fi (C.J.E.L.-A.) \\ * Correspondence: suvi.itkonen@helsinki.fi; Tel.: +358-44-356-1209
}

Received: 25 June 2018; Accepted: 7 August 2018; Published: 9 August 2018

\begin{abstract}
Fluid milk products are systematically, either mandatorily or voluntarily, fortified with vitamin D in some countries but their overall contribution to vitamin D intake and status worldwide is not fully understood. We searched the PubMed database to evaluate the contribution of vitamin D-fortified fluid milk products (regular milk and fermented products) to vitamin D intake and serum or plasma 25-hydroxyvitamin D (25(OH)D) status in observational studies during 1993-2017. Twenty studies provided data on $25(\mathrm{OH}) \mathrm{D}$ status $(n=19,744)$, and 22 provided data on vitamin D intake $(n=99,023)$. Studies showed positive associations between the consumption of vitamin D-fortified milk and $25(\mathrm{OH}) \mathrm{D}$ status in different population groups. In countries with a national vitamin D fortification policy covering various fluid milk products (Finland, Canada, United States), milk products contributed $28-63 \%$ to vitamin D intake, while in countries without a fortification policy, or when the fortification covered only some dairy products (Sweden, Norway), the contribution was much lower or negligible. To conclude, based on the reviewed observational studies, vitamin D-fortified fluid milk products contribute to vitamin D intake and 25(OH)D status. However, their impact on vitamin D intake at the population level depends on whether vitamin $\mathrm{D}$ fortification is systematic and policy-based.
\end{abstract}

Keywords: dairy; vitamin D; vitamin D-fortified milk; vitamin D intake; vitamin D fortification; 25-hydroxyvitamin D

\section{Introduction}

Vitamin D plays an important role in bone health, being necessary for calcium absorption [1]. Low vitamin D status in terms of low serum 25-hydroxyvitamin D (S-25(OH)D) concentration has also been linked to the increased risk of some common chronic diseases, such as type 2 diabetes or cardiovascular disease [2]. In Northern latitudes, especially in the wintertime, ultraviolet B (UVB) radiation is too low for dermal synthesis of vitamin D [3]. As there are only a few natural vitamin D-rich foods, such as fish, egg yolk, and some wild mushrooms [1], some countries, particularly populations at high latitudes, have initiated national policies of fortifying certain foods with vitamin $\mathrm{D}$ to prevent vitamin D deficiency. Usually these vitamin D-fortified products are low-fat milk, fat spreads, breakfast cereals, and certain baby foods $[4,5]$. To better cover different population groups with differing food habits, a wider vitamin $\mathrm{D}$ fortification of different products instead of concentrating on only a few staple foods has been suggested [5].

To our knowledge, a portion of milk products are systematically, either mandatorily or voluntarily, fortified with vitamin D only in Finland, Norway, Sweden, Canada, and United States (Table 1) [6-12]. In Finland, the recommended fortification level of all fluid milks except some organic products 
is currently $1 \mu \mathrm{g} / 100 \mathrm{~g}$, but some products with a concentration of $2 \mu \mathrm{g} / 100 \mathrm{~g}$ are available on the market $[6,7]$. The fortification is voluntary, but all manufacturers unanimously follow the recommendations. In Norway, only one type of milk is recommended to be fortified with vitamin $\mathrm{D}$ at a concentration of $0.4 \mu \mathrm{g} / 100 \mathrm{~g}$ [8]. Sweden recently doubled the fortification levels of fluid milks to $1 \mu \mathrm{g} / 100 \mathrm{~g}$ and extended the mandatory fortification to cover all fluid milk products with $<3 \%$ fat $[9,10]$. Health Canada has also proposed increasing the mandatory vitamin D fortification of fluid milks from around $1 \mu \mathrm{g} / 100 \mathrm{~g}$ to $2 \mu \mathrm{g} / 100 \mathrm{~g}$ as a consequence of the inadequate vitamin D intake among the population [11]. In the United States, fluid milks can be fortified with vitamin D by around $1 \mu \mathrm{g} / 100 \mathrm{~g}$; the fortification is not mandate at the federal level, but most states mandate fortification [12]. In other countries, such as United Kingdom, Ireland, Spain, and Australia, the fortification is not systematic, but there is a varying number of vitamin D-fortified milk products available [13-17]. However, data on their proportion to the total amount of dairy products in different countries is not easily accessed due to fluctuations in the market. This causes a knowledge gap on the prevalence of vitamin $\mathrm{D}$ fortified fluid milks and their contribution to vitamin D intake worldwide.

In the latest updated systematic review and meta-analysis on the effects of vitamin D fortification in randomised controlled trials (RCT), 12 of the 16 included studies used different milk products, such as fluid milk or milk powder, as a carrier of vitamin D [18]. Four of these studies used vitamin D-fortified milk and two used vitamin D-fortified yoghurt drinks. All of the studies showed the efficacy of the studied milk products to increase the S-25(OH)D concentration or decrease the decline in S-25(OH)D status during the wintertime relative to the control group [19-24]. Further, in Finland, the vitamin $\mathrm{D}$ fortification of fluid milks has been shown to improve the S-25(OH)D status independently among regular milk users after extensive changes in the national vitamin $\mathrm{D}$ fortification policy in an 11-year follow-up study [25].

The aim of this review was to investigate the contribution of vitamin D-fortified fluid milk products (regular milk and fermented products, such as sour milk and yoghurt) (i) to vitamin D intake; and (ii) to vitamin D status $(25(\mathrm{OH}) \mathrm{D}$ concentration in plasma or serum in observational studies with a special focus on differences possibly caused by different vitamin $\mathrm{D}$ fortification policies. 
Table 1. Countries with a vitamin D fortification policy of fluid milk products.

\begin{tabular}{|c|c|c|c|c|}
\hline Country & Vitamin D-Fortified Milk Products & Type of Fortification & Added Amount of Vitamin D & New Proposed Amounts of Vitamin D \\
\hline Finland $[6,7]$ & fluid milk products (milk, yoghurt, sourmilk) * & voluntary & $1 \mu \mathrm{g} / 100 \mathrm{~g}$ & na \\
\hline Norway [8] & extra low-fat milk (also lactose free) & voluntary & $0.4 \mu \mathrm{g} / 100 \mathrm{~g}$ & na \\
\hline Sweden $[9,10]$ & low-fat milk (max $1.5 \%$ fat) & mandatory & $0.38-0.50 \mu \mathrm{g} / 100 \mathrm{~g}$ & $\begin{array}{l}0.95-1.10 \mu \mathrm{g} / 100 \mathrm{~g} \text { for milk }<3 \% \text { fat } \\
0.75-1.10 \mu \mathrm{g} / 100 \mathrm{~g} \text { for fermented milk }<3 \% \text { fat }\end{array}$ \\
\hline Canada [11] & milk & mandatory & $0.825-1.125 \mu \mathrm{g} / 100 \mathrm{~g}$ & $2 \mu \mathrm{g} / 100 \mathrm{~g}$ \\
\hline United States [12] & $\begin{array}{l}\text { fluid milk (also acidified milk and cultured } \\
\text { milk), yoghurt }\end{array}$ & voluntary $\ddagger$ & $\begin{array}{c}1.05 \mu \mathrm{g} / 100 \mathrm{~g} \text { for milk } \\
2.225 \mu \mathrm{g} / 100 \mathrm{~g} \text { for yoghurt } \S\end{array}$ & na \\
\hline
\end{tabular}

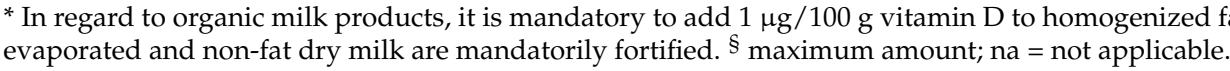




\section{Materials and Methods}

\subsection{Data Sources and Search Strategy}

The literature search was done in the PubMed database at the end of December 2017. The search terms were the following combination of keywords: "vitamin D" [MeSH Terms] OR "vitamin D" [All Fields] OR "ergocalciferols" [MeSH Terms] OR "ergocalciferols" [All Fields]) AND (dairy [All Fields] OR ("milk, human" [MeSH Terms] OR ("milk" [All Fields] AND "human" [All Fields]) OR "human milk" [All Fields] OR "milk" [All Fields] OR "milk" [MeSH Terms])) AND (fortification [All Fields] OR fortified [All Fields]". We limited the search to articles that had the search terms in their title, abstract or among keywords. The data search was restricted to the last 25 years from 1993 to 2017.

\subsection{Eligibility and Study Selection}

Two independent authors reviewed the titles and abstracts of all identified studies and selected observational studies that reported either vitamin D intake or $25(\mathrm{OH}) \mathrm{D}$ status in plasma or serum for full-text screening. Among the full-texts, the eligibility of the articles was screened using the following exclusion criteria: full-text in a language other than English, studies with disease outcomes, participants / patient groups with diagnosed diseases, participants aged less than one year, studies in which the contribution of growing up milks (special products marketed for 1 to 3-year-olds) could not be separated from that of other fluid milks, RCTs, and reviews. In addition, nationally representative study reports in local languages other than English were searched to cover vitamin D intake data from all countries with vitamin $\mathrm{D}$ fortification policy of fluid milks.

\subsection{Data Extraction}

The following information was extracted from eligible studies: first author's name, publication year, country, number and age range of subjects, dietary assessment method, total and/or dietary vitamin D intake (vitamin D intake studies), vitamin D intake from milk (vitamin D intake studies), contribution of milk to vitamin D intake (vitamin D intake studies), latitude (25(OH)D studies), season that blood was drawn $(25(\mathrm{OH}) \mathrm{D}$ studies), $25(\mathrm{OH}) \mathrm{D}$ assay method and quality control of assay $(25(\mathrm{OH}) \mathrm{D}$ studies $)$, and $25(\mathrm{OH}) \mathrm{D}$ concentrations $(25(\mathrm{OH}) \mathrm{D}$ studies $)$. The results were stratified by the population groups as follows: "children and adolescents" (vitamin D and 25(OH)D studies), "pregnant women and mother-child pairs" (25(OH)D studies), and "adults, elderly, and all age groups" (vitamin $\mathrm{D}$ and $25(\mathrm{OH}) \mathrm{D}$ studies). In addition, the results were reported by country. In some cases, the results were stratified by supplement use or other factors, depending on the original study design. In $25(\mathrm{OH}) \mathrm{D}$ studies, the role of vitamin D-fortified milk on vitamin D status was examined as a determinant of vitamin D status or as a comparison of the $25(\mathrm{OH}) \mathrm{D}$ status between low or non-users of vitamin D-fortified milk and more frequent users. If the contribution of milk to total vitamin D intake was not provided, it was calculated from the reported total intake and vice versa. International units were converted to micrograms, and $25(\mathrm{OH}) \mathrm{D}$ concentrations in $\mathrm{ng} / \mathrm{ml}$ were converted to $\mathrm{nmol} / \mathrm{L}$. In this study, we referred to the Institute of Medicine threshold for S-25(OH)D status, where $\leq 30 \mathrm{nmol} / \mathrm{L}$ is vitamin D deficient, $30-49.9 \mathrm{nmol} / \mathrm{L}$ is insufficient, and $\geq 50 \mathrm{nmol} / \mathrm{L}$ is sufficient [26].

\section{Results}

Figure 1 shows the literature search and study selection process. We found 337 articles that were published between 1993 and 2017, and their titles and abstracts were scanned. Fifty-one full-text review papers were selected. Of these, two were unavailable and the corresponding author could not be reached, and 15 were not relevant to the research questions. Thus, 34 papers were included in the review process. Of these, 20 provided data on the $25(\mathrm{OH}) \mathrm{D}$ status, and 20 provided data on vitamin $\mathrm{D}$ intake. Additionally, intake data in national surveys covering countries with a fluid milk vitamin D fortification policy that were not covered in the PubMed search (Norway, Sweden) were explored. One Norwegian [27] and one Swedish report [28] in local language were found and were included 
to provide data on vitamin D intake and the contribution of milk in those countries. Nationally representative data from other countries with a vitamin $\mathrm{D}$ fortification policy were already found in the literature search.

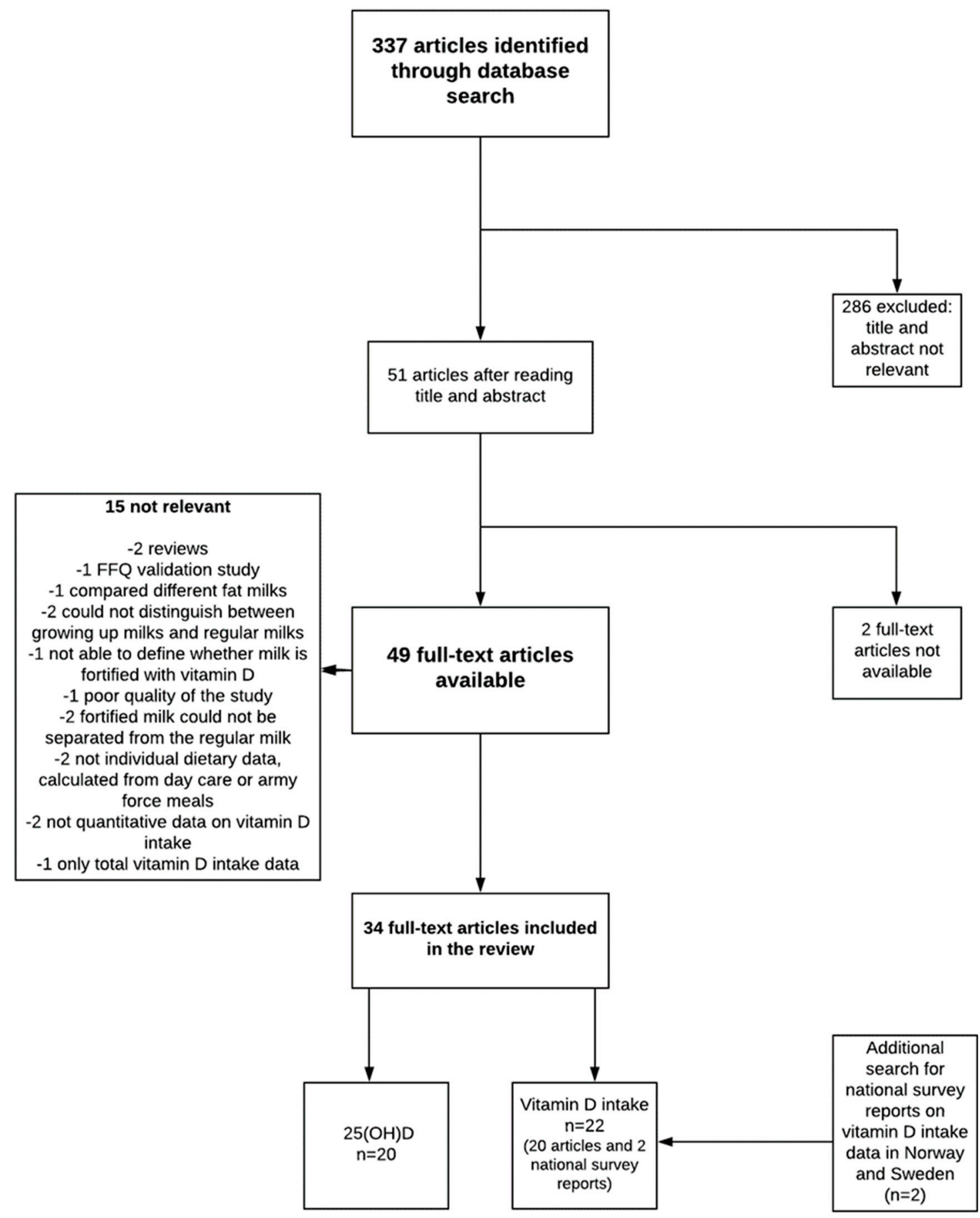

Figure 1. Literature search and study selection process.

\subsection{Contribution of Vitamin D-Fortified Milk to Vitamin D Intakes}

For this review, 22 observational studies reported data on the contribution of vitamin D-fortified milk to vitamin D intake including 99,023 subjects (Table 2). Data from the following countries were provided: United States (6 studies), Canada (4), Finland (4), Ireland (2), Australia (1), Norway (1), Spain (1), Sweden (1), and United Kingdom (1). Additionally, one study provided data from both the United 
States and Canada. Various methods to assess vitamin D intake were used: food records (8 studies), $24 \mathrm{~h}$ recalls (7), food frequency questionnaires (FFQ) (4), one-week diet history (1), household food diary (1), and both FFQ and food records (1).

\subsubsection{Children and Adolescents}

In the studies of Irish and British children and adolescents, the total vitamin $\mathrm{D}$ intakes were 2.8-3.5 $\mu \mathrm{g} /$ day and dietary intakes were 1.6-2.6 $\mu \mathrm{g} /$ day [13-15]. Fortified milks provided $0.4 \mu \mathrm{g} / \mathrm{day}$ or less vitamin D [13-15]. It is notable that the consumption of vitamin D-fortified milk was not common; in the study of Black et al. [13], only $4-5 \%$ of subjects consumed vitamin D-fortified milk. In contrast, in countries with policy-based vitamin D fortification, i.e., in the United States, Canada, and Finland, the mean dietary vitamin D intakes in children were 4.4-5.9 $\mu \mathrm{g} /$ day, and 2.3-3.3 $\mu \mathrm{g} / \mathrm{day}$ of that originated from milk products, covering more than half of the total dietary intake [29-32].

\subsubsection{Adults and the Elderly, and Studies Including All Age Groups}

In Spain and Australia, some of the fluid milks on the market are fortified with vitamin D and studies conducted in these countries among the adult population showed that the contribution of milk to total vitamin D intake was 15-18\%, with total intakes being 3.5 and $4.4 \mu \mathrm{g} /$ day, respectively [16,17]. In a Canadian population-based study among adults, the total vitamin $\mathrm{D}$ intake was shown to be $5.6 \mu \mathrm{g}$ /day among females and $4.8 \mu \mathrm{g}$ /day among males, and milk contributed $48 \%$ of the total vitamin D intake among females and 63\% among males [33]. In other large American and Canadian population-based studies covering all age groups, 1.9-2.9 $\mathrm{gg}$ of vitamin D ingested per day originated from milk, while mean total vitamin D intakes ranged from 4.2 to $9.8 \mu \mathrm{g} /$ day and dietary intakes from 3.9 to $7.0 \mu \mathrm{g} /$ day, milk contributing $44-49 \%$ of the vitamin D intake [33-37]. In a smaller study carried out among the adult population in the United States as well in a Canadian study on Inuit and Inuvialuit women, vitamin D intakes were similar to those found in the larger studies; however, the contribution of milk to vitamin D intake was slightly lower, 31-43\% [38,39]. In line with the newer studies, in two studies carried out among elderly people in the United States that were published in the 1990s, half of the vitamin D intake originated from milk [40,41]. The recent representative population-based study in Finland [25] showed that $34 \%$ of dietary vitamin D intake originated from vitamin D-fortified fluid milk products which is similar to the proportion observed in the latest National FINDIET Study-28-39\%, varying between age and sex groups [42]. Dietary vitamin D intakes in the study of Jääskeläinen et al. were the highest among all of the studies included in this review: $14 \mu \mathrm{g} /$ day among men and $12 \mu \mathrm{g} /$ day among women [25]. Data on the contributions of milk to vitamin D intake in other Nordic European countries following the implementation of a national vitamin $\mathrm{D}$ fortification policy have also been provided. The latest Norwegian national dietary survey reported that extra-skimmed milk, the only vitamin D-fortified milk in Norway, provided $4 \%$ of dietary vitamin D intake, with the mean dietary vitamin D intake being $6 \mu \mathrm{g} /$ day [27]. Despite the wider milk fortification policy in Sweden, only $12 \%$ of dietary vitamin D intake originated from milk products in the Swedish national survey, with the mean dietary vitamin D intake being $7 \mu \mathrm{g} /$ day [28]. 
Table 2. Studies on the contribution of milk to total or dietary vitamin D intake.

\begin{tabular}{|c|c|c|c|c|c|c|c|c|}
\hline Reference & Country & $\begin{array}{c}\text { Study } \\
\text { Population }\end{array}$ & $\begin{array}{l}\text { Dietary Assessment } \\
\text { Method }\end{array}$ & $\begin{array}{l}\text { Total/Dietary Vitamin D } \\
\text { Intake ( } \mu \mathrm{g} / \text { day) }\end{array}$ & $\begin{array}{c}\text { SD } \\
\text { (or SEM *) }\end{array}$ & $\begin{array}{l}\text { Vitamin D Intake from } \\
\text { (fortified) Fluid Milk or } \\
\text { Related Products ( } \mu \mathrm{g} / \text { day) }\end{array}$ & SD & $\begin{array}{c}\text { Contribution of } \\
\text { (Fortified) Milk to Total } \\
\text { or Dietary Vitamin D } \\
\text { Intake (\%) }\end{array}$ \\
\hline \multicolumn{9}{|c|}{ Children and adolescents } \\
\hline $\begin{array}{l}\text { Black et al. } \\
\text { (2014) [13] }\end{array}$ & Ireland & $\begin{array}{c}594 \text { children, } \\
5-12 \text { years and } \\
441 \text { teenagers, } \\
13-17 \text { years }\end{array}$ & $\begin{array}{l}\text { 7-day (semi-) } \\
\text { weighted food record }\end{array}$ & $\begin{array}{c}\text { Total/dietary intake } \\
5-8 \text { years: } 2.8 / 1.9 \\
9-12 \text { years: } 2.8 / 2.2 \\
13-17 \text { years: } 3.2 / 2.6\end{array}$ & $\begin{array}{l}2.4 / 1.1 \\
2.1 / 1.3 \\
2.5 / 1.8\end{array}$ & $\begin{array}{l}\text { Fortified milk: } 0.1 \\
\text { Milk and yoghurt: } 0.3-0.4\end{array}$ & na & $\begin{array}{c}\text { Total intake } \\
\text { Fortified milk: } 2-3 \% \\
\text { Milk and yoghurt: } \\
10-13 \%\end{array}$ \\
\hline $\begin{array}{l}\text { Cole et al. } \\
(2010)[29]\end{array}$ & $\begin{array}{l}\text { United } \\
\text { States }\end{array}$ & $\begin{array}{l}290 \text { children, } \\
1-5 \text { years }\end{array}$ & 3-day food record & Dietary intake: 4.4 & 3.0 & Fortified milk: $2.7^{\dagger}$ & na & $\begin{array}{c}\text { Dietary intake } \\
\text { Fortified milk: } 62 \%\end{array}$ \\
\hline $\begin{array}{l}\text { Cribb et al. } \\
\text { (2015) [14] }\end{array}$ & $\begin{array}{l}\text { United } \\
\text { Kingdom }\end{array}$ & $\begin{array}{l}755 \text { children, } \\
1.5 \text { years and } \\
3.5 \text { years }\end{array}$ & 3-day food diary & $\begin{array}{l}\text { Dietary intake } \\
1.5 \text { years: } 1.6 \\
3.5 \text { years: } 1.8\end{array}$ & $\begin{array}{l}1.5 \\
1.4\end{array}$ & $\begin{array}{l}\text { Yoghurt, cheese and milk } \\
1.5 \text { years: } 0.035 \mu \mathrm{g} / \mathrm{MJ} / \text { day } \\
3.5 \text { years: } 0.023 \mu \mathrm{g} / \mathrm{MJ} / \text { day }\end{array}$ & $\begin{array}{l}0.02 \mu \mathrm{g} / \mathrm{MJ} / \text { day } \\
0.02 \mu \mathrm{g} / \mathrm{MJ} / \text { day }\end{array}$ & $\begin{array}{c}\text { Dietary intake } \\
\text { Yoghurt, cheese and milk } \\
1.5 \text { years: } 9 \% \\
3.5 \text { years: } 6 \%\end{array}$ \\
\hline $\begin{array}{l}\text { Hennessy et al. } \\
\text { (2016) [15] }\end{array}$ & Ireland & $\begin{array}{l}500 \text { children, } \\
1-4 \text { years }\end{array}$ & $\begin{array}{l}\text { 4-day weighted } \\
\text { food diary }\end{array}$ & $\begin{array}{c}\text { Total intake } \\
\text { All subjects: } 3.5 \\
\text { Fortified food consumers: } 3.2\end{array}$ & $\begin{array}{l}3.7 \\
2.7\end{array}$ & $\begin{array}{l}\text { Fortified milk } \\
\text { All subjects: } 0.1 \\
\text { Fortified food } \\
\text { consumers: } 0.1\end{array}$ & na & $\begin{array}{c}\text { Total intake } \\
\text { All subjects: } 2 \% \\
\text { Fortified food consumers, } \\
\text { supplement non-users: } \\
13 \%\end{array}$ \\
\hline $\begin{array}{l}\text { Mark et al. } \\
(2011)[30]\end{array}$ & Canada & $\begin{array}{l}159 \text { children, } \\
8-11 \text { years }\end{array}$ & $3 \times 24$ h recalls & Total/dietary intake: 6.6/5.6 & $4.3 / 3.5$ & Milk: $3.3^{\dagger}$ & na & $\begin{array}{l}\text { Total/dietary intake } \\
\text { Milk: } 49 / 58 \%\end{array}$ \\
\hline $\begin{array}{l}\text { Piirainen et al. } \\
\text { (2007) [32] }\end{array}$ & Finland & $\begin{array}{l}36 \text { children, } \\
4 \text { years }\end{array}$ & 4-day food record & Total/dietary intake: 7.9/4.5 & $\begin{array}{l}6.3-9.6 / \\
3.8-5.1 \S \\
\end{array}$ & 2.3 & $2.0-2.6^{\S}$ & $\begin{array}{l}\text { Total intake } \\
\text { Milk: } 54 \%\end{array}$ \\
\hline $\begin{array}{l}\text { Soininen et al. } \\
\text { (2016) [31] }\end{array}$ & Finland & $\begin{array}{l}374 \text { children, } \\
6-8 \text { years }\end{array}$ & 4-day food record & Total/dietary intake: 7.7/5.9 & $\mathrm{na} / 2.1$ & $\begin{array}{l}\text { Fluid milk: } 2.9 \\
\text { All milk products: } 3.1\end{array}$ & $\begin{array}{l}1.5 \\
1.4\end{array}$ & $\begin{array}{c}\text { Total/dietary intake } \\
\text { Fluid milk: } 38 / 49 \% \\
\text { All milk products: } \\
40 / 52 \%\end{array}$ \\
\hline \multicolumn{9}{|c|}{ Adults and the elderly } \\
\hline $\begin{array}{l}\text { Amcoff et al. } \\
\text { (2012) [28] }\end{array}$ & Sweden & $\begin{array}{l}1797 \text { adults, } \\
18-80 \text { years }\end{array}$ & 4-day food diary & $\begin{array}{l}\text { Dietary intake } \\
\text { Women: } 6.4 \\
\text { Men: } 7.6\end{array}$ & $4.2 / 5.4$ & na & na & $\begin{array}{c}\text { Dietary intake } \\
\text { Milk products: } 12 \%\end{array}$ \\
\hline $\begin{array}{l}\text { Gonzalez- } \\
\text { Rodriguez et al. } \\
\text { (2013) [16] }\end{array}$ & Spain & $\begin{array}{l}418 \text { adults, } \\
18-60 \text { years }\end{array}$ & $24 \mathrm{~h}$ recall & Total/dietary intake: $3.5 / 3.2$ & $4.0 / 3.8$ & Dairy products: $0.5^{+}$ & na & $\begin{array}{c}\text { Total/dietary intake } \\
\text { Dairy products: } 15 / 17 \%\end{array}$ \\
\hline
\end{tabular}


Table 2. Cont

\begin{tabular}{|c|c|c|c|c|c|c|c|c|}
\hline Reference & Country & $\begin{array}{c}\text { Study } \\
\text { Population }\end{array}$ & $\begin{array}{c}\text { Dietary Assessment } \\
\text { Method }\end{array}$ & $\begin{array}{l}\text { Total/Dietary Vitamin D } \\
\text { Intake ( } \mu \mathrm{g} / \text { day })\end{array}$ & $\begin{array}{c}\text { SD } \\
\text { (or SEM *) }\end{array}$ & $\begin{array}{l}\text { Vitamin D Intake from } \\
\text { (fortified) Fluid Milk or } \\
\text { Related Products ( } \mu \mathrm{g} / \text { day) }\end{array}$ & SD & $\begin{array}{c}\text { Contribution of } \\
\text { (Fortified) Milk to Total } \\
\text { or Dietary Vitamin D } \\
\text { Intake (\%) }\end{array}$ \\
\hline $\begin{array}{l}\text { Holm Totland } \\
\text { et al. (2012) [27] }\end{array}$ & Norway & $\begin{array}{l}1787 \text { adults, } \\
18-70 \text { years }\end{array}$ & $24 \mathrm{~h}$ recall & $\begin{array}{c}\text { Total/dietary intake } \\
\text { Women: } 10 / 4.9 \\
\text { Men: } 12 / 6.7\end{array}$ & $\begin{array}{l}\mathrm{na} / 4.3 \\
\mathrm{na} / 5.7\end{array}$ & na & na & $\begin{array}{c}\text { Dietary intake } \\
\text { Vitamin D fortified } \\
\text { extra-skimmed milk: } 4 \%\end{array}$ \\
\hline $\begin{array}{l}\text { Jayaratne et al. } \\
\text { (2013) [17] }\end{array}$ & Australia & $\begin{array}{l}785 \text { adults, } \\
\geq 31 \text { years }\end{array}$ & FFQ & Total intake: 4.4 & 4.0 & $\begin{array}{c}\text { Dairy and related products } \\
\text { including margarine: } 1.9^{+} \\
\text {Milk: } 0.8^{+} \\
\text {Yoghurt: } 0.3^{+}\end{array}$ & $\begin{array}{l}\text { na } \\
\text { na } \\
\text { na }\end{array}$ & $\begin{array}{c}\text { Total intake } \\
\text { Dairy and related } \\
\text { products including } \\
\text { margarine: } 43 \% \\
\text { Milk: } 18 \% \\
\text { Yoghurt: } 6 \%\end{array}$ \\
\hline $\begin{array}{l}\text { Jääskeläinen } \\
\text { et al. (2017) [25] }\end{array}$ & Finland & $\begin{array}{l}3635 \text { adults, } \\
\geq 30 \text { years }\end{array}$ & FFQ & $\begin{array}{l}\text { Dietary intake } \\
\text { Men: } 14 \\
\text { Women: } 12 \\
\end{array}$ & $\begin{array}{l}14-15 \S \\
11-12 \S\end{array}$ & na & na & $\begin{array}{c}\text { Dietary intake } \\
\text { Fluid milk products: } 34 \%\end{array}$ \\
\hline $\begin{array}{l}\text { Kinyamu et al. } \\
\text { (1998) [41] }\end{array}$ & $\begin{array}{l}\text { United } \\
\text { States }\end{array}$ & $\begin{array}{l}376 \text { elderly } \\
\text { women, } \\
65-77 \text { years }\end{array}$ & 7-day food record & $\begin{array}{c}\text { Total intake } \\
\text { Supplement non-users: } 3.5 \\
\text { Supplement users: } 13.4\end{array}$ & $\begin{array}{l}2.2 \\
2.0\end{array}$ & $\begin{array}{c}\text { Milk } \\
\text { Supplement non-users: } 2.0 \\
\text { Supplement users: } 1.8\end{array}$ & $\begin{array}{l}1.6 \\
1.5\end{array}$ & $\begin{array}{l}\text { Total intake } \\
\text { Milk: } 51 \%\end{array}$ \\
\hline $\begin{array}{l}\text { Kolahdooz et al. } \\
\text { (2013) [38] }\end{array}$ & Canada & $\begin{array}{l}203 \text { Inuit and } \\
\text { Inuvialuit } \\
\text { women, } \\
19-44 \text { years }\end{array}$ & FFQ & $\begin{array}{c}\text { All subjects: } 6.0 \ddagger \\
\text { Traditional food eaters: } 7.1 \ddagger \\
\text { Non-traditional food } \\
\text { eaters: } 4.9 \ddagger\end{array}$ & $\begin{array}{l}6.3 \\
5.3 \\
3.2\end{array}$ & $\begin{array}{l}\text { Dairy group (milk, yoghurt, } \\
\text { cheese and eggs) } \\
\text { Traditional food eaters: } 2.2 \\
\text { Non-traditional food } \\
\text { eaters: } 1.9\end{array}$ & $\begin{array}{l}\text { na } \\
\text { na }\end{array}$ & $\begin{array}{c}\text { Dairy group (milk, } \\
\text { yoghurt, cheese and eggs) } \\
\text { Traditional food eaters: } \\
31 \% \ddagger \\
\text { Non-traditional food } \\
\text { eaters: } 39 \% \ddagger \\
\end{array}$ \\
\hline $\begin{array}{l}\text { Levy et al. } \\
\text { (2015) [39] }\end{array}$ & $\begin{array}{l}\text { United } \\
\text { States }\end{array}$ & $\begin{array}{l}743 \text { adults, } \\
20-65 \text { years }\end{array}$ & one week diet history & $\begin{array}{c}\text { Total intake } \\
\text { Winter season: } 4.5 \\
\text { Summer season: } 4.3\end{array}$ & $\begin{array}{l}4.0 \\
3.2\end{array}$ & $\begin{array}{c}\text { Dairy products } \\
\text { Winter season: } 1.9 \\
\text { Summer season: } 1.9\end{array}$ & $\begin{array}{l}2.5 \\
3.8\end{array}$ & $\begin{array}{c}\text { Dietary intake } \\
\text { Winter season: } 43 \% \\
\text { Summer season: } 41 \%\end{array}$ \\
\hline $\begin{array}{l}\text { Moore et al. } \\
\text { (2014) [37] }\end{array}$ & $\begin{array}{l}\text { United } \\
\text { States }\end{array}$ & $\begin{array}{l}9719 \text { adults, } \\
\geq 19 \text { years }\end{array}$ & $24 \mathrm{~h}$ recall & $\begin{array}{c}\text { Total/dietary intake } \\
8.6 / 4.4\end{array}$ & $0.3 / 0.1$ * & $\begin{array}{l}\text { Milk and milk drinks: } 1.7^{\dagger} \\
\text { Fortified milk and milk } \\
\text { products: } 1.9^{\dagger}\end{array}$ & $\begin{array}{l}\text { na } \\
\text { na }\end{array}$ & $\begin{array}{c}\text { Total/dietary intake } \\
\text { Milk and milk drinks: } \\
20 / 39 \% \\
\text { Fortified milk and milk } \\
\text { products: } 22 / 44 \%\end{array}$ \\
\hline $\begin{array}{l}\text { O'Dowd et al. } \\
\text { (1993) [41] }\end{array}$ & $\begin{array}{l}\text { United } \\
\text { States }\end{array}$ & $\begin{array}{l}109 \text { elderly, } \\
>60 \text { years }\end{array}$ & $\begin{array}{l}\text { FFQ or 3-day } \\
\text { dietary record }\end{array}$ & $\begin{array}{l}\text { Total/dietary intake } \\
\text { All subjects: } 9.5 / \\
\text { Supplement non-users: } 7.3\end{array}$ & $5.1 / 2.5$ & $\begin{array}{l}\text { Fortified milk } \\
\text { All subjects: } 4.7\end{array}$ & 1.9 & $\begin{array}{c}\text { Total intake } \\
\text { Fortified milk: } 50 \%\end{array}$ \\
\hline
\end{tabular}


Table 2. Cont.

\begin{tabular}{|c|c|c|c|c|c|c|c|c|}
\hline Reference & Country & $\begin{array}{c}\text { Study } \\
\text { Population }\end{array}$ & $\begin{array}{c}\text { Dietary Assessment } \\
\text { Method }\end{array}$ & $\begin{array}{l}\text { Total/Dietary Vitamin D } \\
\text { Intake ( } \mu \mathrm{g} / \text { day })\end{array}$ & $\begin{array}{c}\text { SD } \\
\text { (or SEM *) }\end{array}$ & $\begin{array}{l}\text { Vitamin D Intake from } \\
\text { (fortified) Fluid Milk or } \\
\text { Related Products ( } \mu \text { g/day) }\end{array}$ & SD & $\begin{array}{c}\text { Contribution of } \\
\text { (Fortified) Milk to Total } \\
\text { or Dietary Vitamin D } \\
\text { Intake (\%) }\end{array}$ \\
\hline $\begin{array}{l}\text { Poliquin et al. } \\
\text { (2009) [33] }\end{array}$ & Canada & $\begin{array}{l}9425 \text { adults, } \\
\geq 25 \text { years }\end{array}$ & $\begin{array}{l}\text { interview-administered } \\
\text { semi-quantitative } \\
\text { FFQ }\end{array}$ & $\begin{array}{l}\text { Total intake from milk and } \\
\text { supplements } \\
\text { Women: } 5.6 \\
\text { Men: } 4.8\end{array}$ & $\begin{array}{l}5.9 \\
5.5\end{array}$ & $\begin{array}{c}\text { Milk } \\
\text { Women: } 2.7 \\
\text { Men: } 3.0\end{array}$ & $\begin{array}{l}2.9 \\
3.5\end{array}$ & $\begin{array}{l}\text { Total intake from milk } \\
\text { and supplements } \\
\text { Women: } 48 \% \\
\text { Men: } 63 \%\end{array}$ \\
\hline $\begin{array}{l}\text { Raulio et al. } \\
\text { (2017) [42] }\end{array}$ & Finland & $\begin{array}{l}1295 \text { adults, } \\
25-64 \text { years }\end{array}$ & $24 \mathrm{~h}$ recall & $\begin{array}{c}\text { Total intake } \\
\text { Women: all women: } 17.5 \\
\text { Supplement non-users: } 8.6 \\
\text { Supplement users: } 24.7 \\
\text { Men: all men: } 17.3 \\
\text { Supplement non-users: } 11.2 \\
\text { Supplement users: } 29.5\end{array}$ & $\begin{array}{c}15.4 \\
6.2 \\
16.8 \\
17.0 \\
7.5 \\
23.1 \\
\end{array}$ & na & na & $\begin{array}{l}\text { Dietary intake } \\
\text { Milk: } 28-39 \% \text {, depending } \\
\text { on age and sex }\end{array}$ \\
\hline \multicolumn{9}{|l|}{ All ages } \\
\hline $\begin{array}{l}\text { Hill et al. } \\
\text { (2012) [36] }\end{array}$ & $\begin{array}{l}\text { United } \\
\text { States and } \\
\text { Canada }\end{array}$ & $\begin{array}{l}7837 \text { US and } \\
4025 \text { Canadian } \\
\text { citizens, } \\
\geq 2 \text { years } \\
\end{array}$ & $\begin{array}{l}\text { 7- to 14-day } \\
\text { household food diary }\end{array}$ & $\begin{array}{l}\text { Total intake } \\
\text { United States: } 4.4 \\
\text { Canada: } 4.2\end{array}$ & $\begin{array}{l}0.03^{*} \\
0.5^{*}\end{array}$ & $\begin{array}{c}\text { Milk } \\
\text { United States: } 2.0 \\
\text { Canada: } 1.9\end{array}$ & $\begin{array}{l}\text { na } \\
\text { na }\end{array}$ & $\begin{array}{l}\text { Total intake } \\
\text { Milk: } 44 \% \text { in both } \\
\text { countries }\end{array}$ \\
\hline $\begin{array}{l}\text { Moore et al. } \\
\text { (2004) [34] }\end{array}$ & $\begin{array}{l}\text { United } \\
\text { States }\end{array}$ & $\begin{array}{l}18931 \text { subjects, } \\
>1 \text { years }\end{array}$ & $24 \mathrm{~h}$ recall & $\begin{array}{c}\text { Total/dietary intake: } \\
5.3-9.8 / 3.9-7.0 \\
\text { depending on age and sex }\end{array}$ & na & na & na & $\begin{array}{c}\text { Dietary intake } \\
\text { Dairy products: } 45-47 \%\end{array}$ \\
\hline $\begin{array}{c}\text { Vatanparast } \\
\text { et al. (2010) [35] }\end{array}$ & Canada & $\begin{array}{l}34789 \text { subjects, } \\
>1 \text { years }\end{array}$ & $24 \mathrm{~h}$ recall & Dietary intake: 6.2 & $0.1^{*}$ & Milk products: 2.9 & na & $\begin{array}{c}\text { Dietary intake } \\
\text { Milk products: } 49 \%\end{array}$ \\
\hline
\end{tabular}

FFQ, food frequency questionnaire; na, not applicable; ${ }^{*} \mathrm{SE}(\mathrm{M})$, standard error (of mean); ${ }^{\dagger}$ calculated from the proportion of milk contribution; ${ }^{\ddagger}$ unclear whether total or dietary vitamin

D intake (3\% supplement users); $\$ 95 \%$ confidence interval. 


\subsection{Associations Between Consumption of Vitamin D-Fortified Milk and 25(OH)D Status}

Twenty observational studies included in this review investigated associations between the consumption of vitamin D-fortified milk and 25(OH)D status $(n=19,744)$ (Table 3). Data from the following countries were provided: United States (5 studies), Canada (4), Finland (3), Sweden (2), Egypt (1), Ireland (1), Jordan (1), Norway (1), Spain (1), and Thailand (1). Various methods were used to assess 25(OH)D concentrations: different immunoassays (13 studies), LC-MS/MS (5) and competitive binding assays (2). Milk consumption was assessed by either a questionnaire (8 studies), FFQ (5), food records (4), $24 \mathrm{~h}$ recall (1), one-week diet history (1) or by both FFQ and food records (1).

\subsubsection{Children and Adolescents}

Among Egyptian children aged 9-11 years $(n=200)$, those who consumed vitamin D-fortified milk less than once a day had a significantly higher risk of vitamin D insufficiency $(\mathrm{S}-25(\mathrm{OH}) \mathrm{D}<$ $50 \mathrm{nmol} / \mathrm{L}$ ) than those who consumed more milk [43]. In Jordan, children who consumed vitamin D-fortified fresh milk had higher S-25(OH)D concentrations than those who consumed unfortified milk (53 nmol/L vs. $43 \mathrm{nmol} / \mathrm{L})(n=93)$ [44]. These two studies did not provide data on the amounts of consumed milk. In Finland, higher consumption of vitamin D-fortified milk was associated with higher S-25(OH)D concentrations among children aged 6-8 years $(n=374)$ [31]. Children who drank at least $450 \mathrm{~g}$ / day of vitamin D-fortified milk had a 72-74\% lower risk of having S-25(OH)D below $50 \mathrm{nmol} / \mathrm{L}$ than those who drank less than $300 \mathrm{~g} /$ day (adjusted for age and sex). However, another study on 10-year-old Finnish children $(n=171)$ found no association between vitamin D-fortified milk consumption frequency and S-25(OH)D status, but among those children with a history of cow's milk allergy (an indicator of milk avoidance), consumption of vitamin D-fortified milk as well as S-25(OH)D concentrations were lower than among their peers without allergy history [45]. Nevertheless, vitamin D supplement use was very common in this population (60\% daily users), and thus was one important determinant of their vitamin D status [45].

A Canadian study in 1-6-year-old children $(n=2468)$ showed that children who drank only non-cow's milk (i.e. vegetable-based milk alternatives or goat's milk) were more than two-fold likely to have an S-25(OH)D concentration $<50 \mathrm{nmol} / \mathrm{L}$ relative to children who drank cow's milk, which is mandatorily fortified in Canada (odds ratio 2.7, 95\% CI 1.6-4.7) [46]. In another sample of Canadian children aged $8-11$ years with a daily mean of 1.3 vitamin D-fortified milk servings $(n=159)$, one daily serving of milk contributed to a $2.9 \mathrm{nmol} / \mathrm{L}$ increase in plasma $25(\mathrm{OH}) \mathrm{D}$ concentration [30]. Further, among 2270 children aged 3-18 years in Canada, those consuming vitamin D-fortified milk daily were more likely to have sufficient $S-25(\mathrm{OH}) \mathrm{D}$ concentration $(\geq 50 \mathrm{nmol} / \mathrm{L})$ than those who drank milk less frequently (odds ratio 2.4, 95\% CI 1.7-3.3) [47,48]. A Spanish study in 9-13-year-old children $(n=102)$ showed that the number of daily dairy servings (mean 2.3 servings) was associated with the S-25(OH)D status [49]. Those who consumed $\geq 2.5$ servings of milk daily had higher S-25(OH)D concentrations than those who did not (53 nmol/L vs. $46 \mathrm{nmol} / \mathrm{L})$ [49]. In Sweden, fortified lean milk consumption (mean $230 \mathrm{~g} /$ day) correlated with S-25(OH)D status in a group of 13-year-old children $(n=165)$ [50]. Among 15-18-year-old adolescents in Norway $(n=890)$, the use of vitamin D-fortified milk was significantly associated with S-25(OH)D status in a multivariate model in boys, but not in girls [51]. Boys who were frequent milk consumers had higher S-25(OH)D concentrations than infrequent consumers, but this was not seen among girls, and no milk consumption data was provided [51].

\subsubsection{Pregnant Women and Mother-Child Pairs}

Two studies carried out in pregnant women in Thailand and Finland also showed an association between vitamin D-fortified milk and vitamin D status [52,53]. Among Thai women $(n=120)$, the consumption of multivitamin-fortified milk containing vitamin D was higher among those with vitamin D sufficiency $(\mathrm{S}-25(\mathrm{OH}) \mathrm{D}$ concentration $>50 \mathrm{nmol} / \mathrm{L})$ in the third trimester than among those 
with insufficiency [52]. Consumption of multivitamin-fortified milk was associated with an increase in S-25(OH)D concentration between the first and third trimester. The mean multivitamin-fortified milk consumption was 1.0 daily serving in the first trimester and 1.4 servings in the third trimester. In a multivariate analysis, non-consumption of multivitamin-fortified milk was an independent predictor of vitamin D deficiency [52]. In a study carried out in 584 mother-child pairs in Finland, modifiers of umbilical cord blood (UCB) 25(OH)D status were studied [53]. The maternal dietary pattern "dairy and sandwich", including vitamin D-fortified milk and margarines, positively contributed to child UCB 25(OH)D status in mother-child pairs in whom an increase was seen in $25(\mathrm{OH}) \mathrm{D}$ concentration when comparing maternal $25(\mathrm{OH}) \mathrm{D}$ status in early pregnancy with UCB $25(\mathrm{OH}) \mathrm{D}$ status, but not in those in whom no increase was seen [53]. Among Jordanian women, no differences in S-25(OH)D concentration were seen among those who consumed vitamin D-fortified milk relative to those who consumed unfortified milk (26 nmol/L vs. $27 \mathrm{nmol} / \mathrm{L})$ [44]. However, their vitamin D status was much worse than that of their children, whose vitamin D status was better if vitamin D-fortified milk was consumed [44].

\subsubsection{Adults, the Elderly, and All Age Groups}

Among adults aged 20-65 years in the United States $(n=743)$, the use of vitamin D-fortified milk was a significant predictor of $\mathrm{S}-25(\mathrm{OH}) \mathrm{D}$ status in the wintertime, but not in the summertime [39]. In an elderly American population aged $>65$ years $(n=376)$ [41], S-25(OH)D status correlated with milk calcium intake from vitamin D-fortified milk (an indicator of milk consumption). Among those who did not use vitamin D supplements, milk calcium was the main determinant of S-25(OH)D status; however, this was not the case among vitamin D supplement users. Among adult ( $\geq 18$ years) Arab-American women $(n=87)$, vitamin D-fortified milk was not an independent determinant of S-25(OH)D status, but their milk consumption was minimal, and S-25(OH)D concentrations were extremely low [54]. In the Canadian National Survey consisting of a population aged 6-79 years $(n=5306)$, those who consumed vitamin D-fortified milk once a day or more had higher S-25(OH)D concentrations than those with consumption of less than once a day [55]. People who consumed milk more than once a day had a mean S-25(OH)D concentration of $75 \mathrm{nmol} / \mathrm{L}$, while the corresponding mean among those who consumed milk less than once a day was $63 \mathrm{nmol} / \mathrm{L}$. In a Swedish study on elderly women aged $>60$ years $(n=116)$, consumption of vitamin D-fortified reduced-fat dairy correlated with S-25(OH)D status, and the intake of two daily portions of fortified milk (300 g) was associated with a $6.2 \mathrm{nmol} / \mathrm{L}$ increment in S-25(OH)D concentration in a multiple linear regression model [56]. Further, in an Irish study of three large cohorts of elderly subjects ( $n=1233, n=1895$, $n=1316)$, vitamin D-fortified milk consumption predicted a higher S-25(OH)D concentration in two of the three cohorts [57]. 
Table 3. Studies in which the contribution of vitamin D-fortified milk to serum or plasma 25-hydroxyvitamin D status was evaluated.

\begin{tabular}{|c|c|c|c|c|c|c|c|}
\hline Reference & $\begin{array}{l}\text { Country } \\
\text { (Latitude) }\end{array}$ & $\begin{array}{l}\text { Season Blood } \\
\text { Drawn }\end{array}$ & Study Population & $\begin{array}{l}\text { 25(OH)D Assay Method } \\
\text { (Quality Control of Assay: } \\
\text { Certificate; CV\% }<15 \% \text { ) }\end{array}$ & $\begin{array}{l}\text { Dietary } \\
\text { Assessment } \\
\text { Method }\end{array}$ & $\begin{array}{l}\text { Serum or Plasma } \\
\text { 25(OH)D nmol/L } \\
\text { Mean (or Median *) }\end{array}$ & $\begin{array}{l}\mathrm{SD}\left(\text { or IQR }{ }^{\dagger} \text { or }\right. \\
\left.95 \% \mathrm{CI}^{\ddagger} \text { or } \mathrm{SE} \mathrm{S}^{\S}\right)\end{array}$ \\
\hline \multicolumn{8}{|l|}{$\begin{array}{l}\text { Children and } \\
\text { adolescents }\end{array}$} \\
\hline $\begin{array}{l}\text { Abu Shady et al. } \\
\text { (2016) [43] }\end{array}$ & Egypt $\left(31^{\circ} \mathrm{N}\right)$ & April, May & $\begin{array}{l}200 \text { children, } \\
9-11 \text { years }\end{array}$ & $\begin{array}{l}\text { Quantitative enzyme } \\
\text { immunoassay } \\
\text { (na; na) }\end{array}$ & Questionnaire & 41 & 14 \\
\hline $\begin{array}{l}\text { Barman et al. } \\
\text { (2015) [50] }\end{array}$ & Sweden $\left(63^{\circ} \mathrm{N}\right)$ & All & $\begin{array}{l}165 \text { children, } \\
13 \text { years }\end{array}$ & $\begin{array}{l}\text { LC-MS/MS } \\
\text { (na; na) }\end{array}$ & FFQ & 51 & 14 \\
\hline Cole et al. (2010) [29] & $\begin{array}{l}\text { United States }\left(33^{\circ}\right. \\
\mathrm{N})\end{array}$ & All & $\begin{array}{l}290 \text { children, } \\
1-5 \text { years }\end{array}$ & $\begin{array}{l}\text { LC-MS/MS } \\
\text { (na; na) }\end{array}$ & 3-day food record & 65 & 19 \\
\hline Lee et al. (2014) [46] & Canada $\left(43^{\circ} \mathrm{N}\right)$ & All & $\begin{array}{l}2468 \text { children, } \\
1-6 \text { years }\end{array}$ & $\begin{array}{c}\text { Diasorin LIAISON } \\
\text { (na; yes except inter CV\% } \\
17.4 \% \text { at high concentrations) }\end{array}$ & Questionnaire & 80 * & $66-99^{+}$ \\
\hline $\begin{array}{l}\text { Mark et al. } \\
\text { (2011) [30] }\end{array}$ & Canada $\left(45^{\circ} \mathrm{N}\right)$ & All & $\begin{array}{l}159 \text { children, } \\
8-11 \text { years }\end{array}$ & $\begin{array}{l}\text { IDS radioimmunoassay } \\
\text { (na; yes) }\end{array}$ & $3 \times 24 \mathrm{~h}$ recalls & $\begin{array}{l}\text { Winter/spring: } 50 \\
\text { Summer/autumn: } 58\end{array}$ & $\begin{array}{l}10 \\
15\end{array}$ \\
\hline $\begin{array}{l}\text { Munasinghe et al. } \\
(2017)[47,48]\end{array}$ & $\begin{array}{l}\text { Canada (various } \\
\text { latitudes) }\end{array}$ & All & $\begin{array}{l}2270 \text { children, } \\
3-18 \text { years }\end{array}$ & $\begin{array}{c}\text { Diasorin LIAISON } \\
\text { (na; yes) }\end{array}$ & FFQ & 62 & $56-69 \ddagger$ \\
\hline $\begin{array}{l}\text { Rodríguez-Rodríguez } \\
\text { et al. (2011) [49] }\end{array}$ & Spain $\left(40^{\circ} \mathrm{N}\right)$ & February & $\begin{array}{l}102 \text { children, } \\
9-13 \text { years }\end{array}$ & $\begin{array}{l}\text { Chemiluminescence } \\
\text { (na; na) }\end{array}$ & $\begin{array}{l}\text { 3-day weighted } \\
\text { food diary }\end{array}$ & 50 & 16 \\
\hline $\begin{array}{l}\text { Rosendahl et al. } \\
\text { (2017) [45] }\end{array}$ & Finland $\left(60^{\circ} \mathrm{N}\right)$ & January-June & $\begin{array}{l}171 \text { children, } \\
10 \text { years }\end{array}$ & $\begin{array}{l}\text { Roche Diagnostics } \\
\text { immunocheminuminescence } \\
\text { (na; na) }\end{array}$ & FFQ & 73 & 22 \\
\hline $\begin{array}{l}\text { Soininen et al. } \\
\text { (2016) [31] }\end{array}$ & Finland $\left(62^{\circ} \mathrm{N}\right)$ & All but July & $\begin{array}{l}374 \text { children, } \\
6-8 \text { years }\end{array}$ & $\begin{array}{c}\text { Diasorin LIAISON } \\
\text { (na; yes) }\end{array}$ & 4-day food record & 69 & 24 \\
\hline $\begin{array}{l}\text { Öberg et al. } \\
\text { (2014) [51] }\end{array}$ & Norway $\left(69^{\circ} \mathrm{N}\right)$ & September-April & $\begin{array}{l}890 \text { children, } \\
15-18 \text { years }\end{array}$ & $\begin{array}{l}\text { LC-MS/MS } \\
\text { (DEQAS; yes) }\end{array}$ & Questionnaire & $\begin{array}{l}\text { Boys: } 41 \\
\text { Girls: } 54\end{array}$ & $\begin{array}{l}21 \\
23\end{array}$ \\
\hline \multicolumn{8}{|c|}{ Pregnant women and mother-child pairs } \\
\hline $\begin{array}{l}\text { Charatcharoenwitthaya } \\
\text { et al. (2013) [52] }\end{array}$ & Thailand $\left(14^{\circ} \mathrm{N}\right)$ & $\begin{array}{l}\text { Winter season: } \\
72 \% \text {, rainy season: } \\
28 \%\end{array}$ & $\begin{array}{l}120 \text { pregnant women, } \\
18-40 \text { years }\end{array}$ & $\begin{array}{l}\text { LC-MS/MS MassCrom } \\
\text { (na; yes) }\end{array}$ & $\begin{array}{l}\text { Interviewed } \\
\text { questionnaire }\end{array}$ & $\begin{array}{l}\text { 1st trimester: } 61 \\
\text { 2nd trimester: } 84 \\
\text { 3rd trimester: } 90\end{array}$ & $\begin{array}{l}17 \\
20 \\
22\end{array}$ \\
\hline $\begin{array}{l}\text { Gharaibeh et al. } \\
\text { (2009) [44] }\end{array}$ & Jordan $\left(31^{\circ} \mathrm{N}\right)$ & June and July & $\begin{array}{l}93 \text { children ( } 4-5 \text { years) } \\
\text { and mothers (mean age } \\
34 \text { years) dyads }\end{array}$ & $\begin{array}{l}\text { IDS ELISA } \\
\text { (na; na) }\end{array}$ & Questionnaire & $\begin{array}{l}\text { Mothers: } 26 \\
\text { Children: } 56\end{array}$ & $\begin{array}{l}10 \\
20\end{array}$ \\
\hline
\end{tabular}


Table 3. Cont.

\begin{tabular}{|c|c|c|c|c|c|c|c|}
\hline Reference & $\begin{array}{l}\text { Country } \\
\text { (Latitude) }\end{array}$ & $\begin{array}{l}\text { Season Blood } \\
\text { Drawn }\end{array}$ & Study Population & $\begin{array}{l}\text { 25(OH)D Assay Method } \\
\text { (Quality Control of Assay: } \\
\text { Certificate; CV\% <15\%) }\end{array}$ & $\begin{array}{l}\text { Dietary } \\
\text { Assessment } \\
\text { Method }\end{array}$ & $\begin{array}{c}\text { Serum or Plasma } \\
\text { 25(OH)D nmol/L } \\
\text { Mean (or Median *) }\end{array}$ & $\begin{array}{l}\text { SD (or IQR }{ }^{\dagger} \text { or } \\
\left.95 \% \mathrm{CI}^{\ddagger} \text { or } \mathrm{SE}^{\S}\right)\end{array}$ \\
\hline $\begin{array}{l}\text { Hauta-alus et al. } \\
\text { (2017) [53] }\end{array}$ & Finland $\left(60^{\circ} \mathrm{N}\right)$ & All & $\begin{array}{l}584 \text { newborns and } \\
\text { mothers (18-43 years) }\end{array}$ & $\begin{array}{c}\text { IDS-iSYS } \\
\text { (DEQAS; yes) }\end{array}$ & FFQ & $\begin{array}{l}\text { Mothers: } 89 \\
\text { Cord blood: } 88\end{array}$ & $\begin{array}{l}19 \\
22\end{array}$ \\
\hline \multicolumn{8}{|l|}{$\begin{array}{l}\text { Adults and the } \\
\text { elderly }\end{array}$} \\
\hline $\begin{array}{l}\text { Burgaz et al. } \\
\text { (2007) [56] }\end{array}$ & Sweden $\left(60^{\circ} \mathrm{N}\right)$ & January-March & $\begin{array}{l}116 \text { elderly women, } \\
61-86 \text { years }\end{array}$ & $\begin{array}{l}\text { IDS EIA } \\
\text { (na; yes) }\end{array}$ & FFQ & 69 & 23 \\
\hline $\begin{array}{l}\text { Hobbs et al. } \\
(2009)[54]\end{array}$ & $\begin{array}{l}\text { United States }\left(42^{\circ}\right. \\
\mathrm{N})\end{array}$ & April & $\begin{array}{l}87 \text { women, } \\
\geq 18 \text { years }\end{array}$ & $\begin{array}{l}\text { Diasorin LIAISON } \\
\text { (na; na) }\end{array}$ & Questionnaire & $\begin{array}{l}\text { Unveiled subjects: } 21^{*} \\
\text { Veiled supplement } \\
\text { users: } 17^{*} \\
\text { Veiled supplement } \\
\text { non-users: } 10^{*}\end{array}$ & $\begin{array}{c}14-34^{\dagger} \\
10-29^{+} \\
5-17^{+}\end{array}$ \\
\hline $\begin{array}{l}\text { Kinyamu et al. } \\
\text { (1998) [41] }\end{array}$ & $\begin{array}{l}\text { United States }\left(41^{\circ}\right. \\
\mathrm{N})\end{array}$ & All & $\begin{array}{l}376 \text { elderly women, } \\
65-77 \text { years }\end{array}$ & $\begin{array}{l}\text { Competitive binding assay } \\
\text { (na; yes) }\end{array}$ & 7-day food record & $\begin{array}{c}\text { Supplement } \\
\text { non-users: } 74 \\
\text { Supplement users: } 88\end{array}$ & $\begin{array}{l}23 \\
28\end{array}$ \\
\hline $\begin{array}{l}\text { Levy et al. } \\
\text { (2015) [39] }\end{array}$ & $\begin{array}{c}\text { United States } \\
\text { (various latitudes) }\end{array}$ & $\begin{array}{l}\text { February-April } \\
\text { and } \\
\text { August-October }\end{array}$ & $\begin{array}{l}743 \text { adults, } \\
20-65 \text { years }\end{array}$ & $\begin{array}{l}\text { Diasorin LIAISON } \\
\text { (College of American } \\
\text { Pathology; na) }\end{array}$ & $\begin{array}{l}\text { One week diet } \\
\text { history }\end{array}$ & $\begin{array}{l}\text { Summer: } 101 \\
\text { Winter: } 93\end{array}$ & $\begin{array}{l}42 \\
39\end{array}$ \\
\hline $\begin{array}{l}\text { McCarroll et al. } \\
\text { (2015) [57] }\end{array}$ & Ireland $\left(52^{\circ} \mathrm{N}\right)$ & All & $\begin{array}{c}3 \text { cohorts }(1233,1895, \\
1316) \text { of elderly subjects, } \\
>60 \text { years }\end{array}$ & $\begin{array}{c}\text { LC-MS } \\
\text { (DEQAS; yes) }\end{array}$ & Questionnaire & $\begin{array}{c}\text { Supplement } \\
\text { non-users: } 46 / 61 / 68 \\
\text { Supplement users: } \\
67 / 83 / 74\end{array}$ & $\begin{array}{l}24 / 32 / 23 \\
27 / 27 / 30\end{array}$ \\
\hline $\begin{array}{l}\text { O'Dowd et al. } \\
\text { (1993) [40] }\end{array}$ & $\begin{array}{l}\text { United States }\left(41^{\circ}\right. \\
\mathrm{N})\end{array}$ & January-May & $\begin{array}{l}109 \text { elderly, } \\
>60 \text { years }\end{array}$ & $\begin{array}{l}\text { Competitive binding assay } \\
\text { (na; yes) }\end{array}$ & $\begin{array}{l}\text { FFQ or 3-day } \\
\text { dietary record }\end{array}$ & $\begin{array}{c}\text { All subjects: } 45 \\
\text { Supplement } \\
\text { non-users: } 40 \\
\text { Supplement users: } 65\end{array}$ & $\begin{array}{l}2 \S \\
2 \S \\
3 \S\end{array}$ \\
\hline \multicolumn{8}{|l|}{ All ages } \\
\hline $\begin{array}{l}\text { Langlois et al. } \\
\text { (2010) [55] }\end{array}$ & $\begin{array}{l}\text { Canada (various } \\
\text { latitudes) }\end{array}$ & All & $\begin{array}{l}5306 \text { subjects, } \\
6-79 \text { years }\end{array}$ & $\begin{array}{l}\text { Diasorin Liaison } \\
\text { (DEQAS; yes) }\end{array}$ & $\begin{array}{l}\text { Interviewed } \\
\text { questionnaire }\end{array}$ & $\begin{array}{c}\text { All subjects } 68 \\
\text { April-October } 70 \\
\text { November-March } 64\end{array}$ & $\begin{array}{l}65-70 \ddagger \\
66-74^{\ddagger} \\
60-68 \ddagger\end{array}$ \\
\hline
\end{tabular}

CI, confidence interval; CV coefficient of variation; DEQAS, Vitamin D External Quality Assessment Scheme; EIA enzyme immunoassay; ELISA enzyme linked immunosorbent assay; FFQ, food frequency questionnaire; IQR interquartile range; LC-MS/MS liquid chromatography-tandem mass spectrometry; SE standard error; 25(OH)D, 25-hydroxyvitamin D. * Median; ${ }^{+} \mathrm{IQR} ;$; $95 \% \mathrm{CI}$; $\$ \mathrm{SE}$ 


\section{Discussion}

Based on these observational studies on vitamin D intake and vitamin D-fortified milk consumption, it seems that in countries with wide vitamin D fortification policies (Finland, Canada, United States), the total vitamin D intake as well as the contribution of milk to total vitamin D intake is higher than in the countries without fortification policies (Ireland, United Kingdom, Spain, Australia). It is notable that in Norway and Sweden, where some of the fluid milks are fortified with vitamin D amounts lower than in Finland, Canada, or United States, the contribution of fluid milk to vitamin D intake was shown to be as low as $4 \%$ and $12 \%$, respectively, compared with around $50 \%$ in the other fortification policy countries.

Concerning the vitamin D status, we observed that the consumption of vitamin D-fortified milk was positively associated with $25(\mathrm{OH}) \mathrm{D}$ status in almost all studies included in this review within heterogeneous population groups, independent of country-specific vitamin D-fortification policies. Even though the consumed amounts of milk varied, the associations between milk and 25(OH)D status were seen also at fairly low consumption levels. Further, the association was seen in different population groups: children (with the exception of 10-year old Finns), teenagers (except in Norwegian girls), adults (except in Arab-American women), pregnant women, and the elderly. This mostly positive association between vitamin D-fortified milk consumption and vitamin D status was supported by a recent standardized representative population-based study in Finland, where the vitamin $\mathrm{D}$ fortification policy of fluid milks, in particular, was shown to be successful in improving vitamin D status in the Finnish population [25]. It would be useful to have systematic follow-up data from the other countries with vitamin D fortification policies, as the present evidence is based mainly on the Finnish follow-up study. Vatanparast et al. [35] stated that despite vitamin D fortification being mandatory in Canada, the vitamin D intakes are inadequate and recently, Canada implemented new guidelines to increase the fortification levels [11]. Sweden has also extended their vitamin D fortification policy [10]; thus, in the following years there is an opportunity to evaluate the effects of vitamin $\mathrm{D}$ fortification at the population level also in those countries.

\subsection{Limitations of the Study}

The studies included in this review were carried out in populations of differing size, age, and gender in numerous countries and at a range of latitudes with different levels of UVB exposure. Different assay methods for $25(\mathrm{OH}) \mathrm{D}$ analysis have been used, increasing the heterogeneity of the studies [58], and not all studies have provided quality control data. LC-MS/MS, which is considered the golden standard and reference method in $25(\mathrm{OH}) \mathrm{D}$ assays [58], was used in $25 \%$ of the reviewed studies. However, as our aim was to investigate the associations between the consumption of vitamin D fortified milk and $25(\mathrm{OH}) \mathrm{D}$ status, the differences among the assays probably do not mitigate the power of the overall conclusions, as the trends in $25(\mathrm{OH}) \mathrm{D}$ concentrations usually remain similar independent of the analysis method used [59]. Of greater importance is that most studies considered the variability of $25(\mathrm{OH}) \mathrm{D}$ concentrations between seasons and took the samples at a time when UVB availability is low or over a short time period or adjusted the data for the season $[39,56]$. Also, the dietary assessment methods used in the studies varied and the validity of the methods was not described in all papers. Some used validated FFQs $[25,47]$ and some only used questionnaires on milk consumption [43,46]. Moreover, the portion sizes used were not defined in all studies. The consumed amounts of milk and the vitamin D contents differed, as did the confounding factors used in statistical analyses. The representativeness of the samples was not described in most of the studies, but representative data from national health surveys in the United States, Canada, Sweden, Norway, and Finland were included when describing the contributions of fluid milk to vitamin D intake $[25,27,28,33-35,37]$. We only searched data from PubMed, and some studies might have been missed in our limited literature search. However, these are probably studies that have not taken a stand on vitamin D fortification of fluid milks as such, and therefore, have not emphasized it in the abstracts 
or in the keywords. Nevertheless, publication bias may have occurred, as some studies that found no association between vitamin D-fortified milk and vitamin D status may not have been published.

\subsection{Future Perspectives in Vitamin D Fortification}

Vitamin D fortification of foodstuffs has proven to be a suitable vehicle to increase vitamin D intake at the population level [5], and the present review shows that vitamin D-fortified fluid milk products contribute to both vitamin D intake and 25(OH)D status. Cashman and Kiely [5], however, stated that the fortification of fluid milks may not be enough. Thus, country-specific staple foods should be chosen as optimal vitamin D carriers based on the results of simulation studies. Also, the biofortification of foodstuffs should be considered [5]. In many countries without a current fortification policy, the option of systematic vitamin D fortification of food is under consideration, and simulation studies have been carried out in recent years. A study using Swedish, British, and Dutch data, for instance, showed that increased fortification of fluid milk to the level currently used in Finland $(1 \mu \mathrm{g} / 100 \mathrm{~g})$ and fortification of margarines to $15 \mu \mathrm{g} / 100 \mathrm{~g}$ would substantially increase vitamin D intake [60]. Another study based on British data [61] revealed that the best option would be the fortification of wheat flour with vitamin $\mathrm{D}$, this being a more efficient option to increase S-25(OH)D concentration than milk alone or combined fortification of milk and wheat flour. In Germany, the effects of fortification on the seasonal variation of S-25(OH)D concentrations were simulated, but milk was not considered to be a good carrier of vitamin D [62]. Simulation studies in Irish and British children showed that the fortification of cow's milk would improve vitamin D intake [14,63]. Further, an Australian simulation demonstrated that with vitamin $\mathrm{D}$ fortification of all milk and breakfast cereals, vitamin D intake would increase almost two-fold [17]. These studies reflect the interest in widening the fortification policies. However, the results of the above-described simulation studies show that fortification of milk products may not be the most effective option in all countries.

\section{Conclusions}

The reviewed studies indicated that in countries with a national vitamin D fortification policy for fluid milks at a level of around $1 \mu \mathrm{g} / 100 \mathrm{~g}$, such as Finland, United States, and Canada, milk products contribute substantially to vitamin D intake, while in countries without a fortification policy or with only a few milk products being mandatorily fortified, the contribution is low. Studies carried out at different latitudes among different population groups have also shown that the consumption of vitamin D-fortified milk is associated with a higher $25(\mathrm{OH})$ D concentration. Based on the reviewed observational studies, vitamin D fortification of milk is an effective vehicle in improving vitamin D intake and 25(OH)D status in populations with adequate average milk consumption. However, other food sources, natural or fortified, as well as national recommendations on the use of vitamin D supplements should not be overlooked when planning national nutrition policies to ensure adequate vitamin D intake.

Author Contributions: Conceptualization: S.T.I., M.E. and C.J.E.L.-A.; Methods: S.T.I. and C.J.E.L.-A.; Data search: S.T.I.; Study Selection: S.T.I. and C.J.E.L.-A.; Data Extraction: S.T.I.; Writing-Original Draft Preparation: S.T.I.; Writing-Review \& Editing: S.T.I., M.E. and C.J.E.L.-A.; Project Administration: S.T.I.; Funding Acquisition: S.T.I.

Funding: This research was funded by [Foundation for Nutrition Research].

Conflicts of Interest: The authors declare no conflict of interest. The funders had no role in the design of the study; in the collection, analyses, or interpretation of data; in the writing of the manuscript, and in the decision to publish the results.

\section{References}

1. Lamberg-Allardt, C.; Brustad, M.; Meyer, H.E.; Steingrimsdottir, L. Vitamin D-A systematic literature review for the 5th edition of the Nordic Nutrition Recommendations. Food Nutr. Res. 2013, 57, 22671. [CrossRef] [PubMed] 
2. Theodoratou, E.; Tzoulaki, I.; Zgaga, L.; Ioannidis, J.P. Vitamin D and multiple health outcomes: Umbrella review of systematic reviews and meta-analyses of observational studies and randomized trials. BMJ 2014, 348, 2035. [CrossRef] [PubMed]

3. O’Neill, C.M.; Kazantzidis, A.; Ryan, M.J.; Barber, N.; Sempos, C.T.; Durazo-Arvizu, R.A.; Jorde, R.; Grimnes, G.; Eiriksdottir, G.; Gudnason, V.; et al. Seasonal changes in vitamin D-effective UVB-availability in Europe and associations with population serum 25-hydroxyvitamin D. Nutrients 2016, 8, 533-538. [CrossRef] [PubMed]

4. European Union. Commission Directive 2006/141/EC on infant formulae and follow-on formulae and amending Directive 1999/21/EC. Off. J. Eur Union 2006, 401, 15.

5. Cashman, K.D.; Kiely, M. Tackling inadequate vitamin D intakes within the population: Fortification of dairy products with vitamin D may not be enough. Endocrine 2016, 251, 38-46. [CrossRef] [PubMed]

6. National Nutrition Council. Report of vitamin D Working Group (Valtion Ravitsemusneuvottelukunta D-Vitamiinityöryhmän Raportti In Finnish). 2010. Available online: https:/ /www.evira.fi/globalassets / vrn/pdf/d-vitamiiniraportti2010.pdf (accessed on 1 January 2018).

7. Ministry of Agriculture and Forestry of Finland. Maa-ja metsätalousministeriön asetus rasvattoman homogenoidun maidon D-vitaminoinnista. Available online: http:/ /www.finlex.fi/fi/laki/alkup/2016/ 20160754 (accessed on 1 March 2018).

8. Nasjonalt råd for Ernaering. Tiltak for å Sikre en God Vitamin D-Status I Befolkningen. 2006. Available online: https: / helsedirektoratet.no/Documents/Om\%20oss/R\%C3\%A5d\%20og\%20utvalg/Nasjonalt\%20r\% C3\%A5d\%20for\%20ern\%C3\%A6ring/Tiltak\%20for\%20\%C3\%A5\%20sikre\%20en\%20god\%20vitamin\% 20D-status\%20i\%20befolkningen\%20IS-1408.pdf (accessed on 1 January 2018).

9. Livsmedelsverket. Livsmedelverkets Föreskrifter (SLVFS 1983:2) om Berikning av Vissa Livsmedel (Food Agency's Order about Fortification of Foodstuffs). Available online: https://www.livsmedelsverket. se/globalassets/om-oss/lagstiftning/berikn---kosttillsk---livsm-spec-gr-fsmp/slvfs-1983-02-kons.pdf (accessed on 1 January 2018).

10. Livsmedelsverket. Livsmedelverkets föreskrifter (LIVSFS 2018:5) om berikning av vissa livsmedel (Food Agency's order about fortification of foodstuffs). Available online: https://www.livsmedelsverket. se/globalassets/om-oss/lagstiftning/berikn---kosttillsk---livsm-spec-gr-fsmp/livsfs-2018-5_web.pdf (accessed on 1 June 2018).

11. Department of Health. Regulations Amending Certain Regulations Made Under the Food and Drugs Act (Nutrition Symbols, Other Labelling Provisions Partially Hydrogenated Oils and Vitamin D.). Can. Gazette. 2018, 152, 6. Available online: http://gazette.gc.ca/rp-pr/p1/2018/2018-02-10/pdf/g1-15206.pdf (accessed on 1 June 2018).

12. Calvo, M.S.; Whiting, S.J. Vitamin D Fortification in North America: Current Status and Future Considerations. In The Handbook of Food Fortification from Concepts to Public Health Applications; Preedy, R.V., Srirajaskanthan, R., Patel, V., Eds.; Springer Science + Business Media: New York, NY, USA, 2013; Volume 2, pp. 259-271.

13. Black, L.J.; Walton, J.; Flynn, A.; Kiely, M. Adequacy of vitamin D intakes in children and teenagers from the base diet, fortified foods and supplements. Public Health Nutr. 2014, 17, 721-731. [CrossRef] [PubMed]

14. Cribb, V.L.; Northstone, K.; Hopkins, D.; Emmett, P.M. Sources of vitamin D and calcium in the diets of preschool children in the UK and the theoretical effect of food fortification. J. Hum. Nutr. Diet. 2015, 28, 583-592. [CrossRef] [PubMed]

15. Hennessy, Á.; Browne, F.; Kiely, M.; Walton, J.; Flynn, A. The role of fortified foods and nutritional supplements in increasing vitamin D intake in Irish preschool children. Eur. J. Nutr. 2017, 56, 1219-1231. [CrossRef] [PubMed]

16. González-Rodríguez, L.G.; Estaire, P.; Peñas-Ruiz, C.; Ortega, R.M.; UCM Research Group VALORNUT (920030). Vitamin D intake and dietary sources in a representative sample of Spanish adults. J. Hum. Nutr. Diet. 2013, 26, 64-72. [CrossRef]

17. Jayaratne, N.; Hughes, M.C.; Ibiebele, T.I.; Van den Akker, S.; Van der Pols, J.C. Vitamin D intake in Australian adults and the modeled effects of milk and breakfast cereal fortification. Nutrition 2013, 29, 1048-1053. [CrossRef] [PubMed]

18. Black, L.J.; Seamans, K.M.; Cashman, K.D.; Kiely, M. An updated systematic review and meta-analysis of the efficacy of vitamin D food fortification. J. Nutr. 2012, 142, 1102-1108. [CrossRef] [PubMed] 
19. McKenna, M.J.; Freaney, R.; Byrne, P.; McBrinn, Y.; Murray, B.; Kelly, M.; Donne, B.; O’Brien, M. Safety and efficacy of increasing wintertime vitamin $\mathrm{D}$ and calcium intake by milk fortification. QJM 1995, 88, 895-898. [PubMed]

20. Keane, E.M.; Healy, M.; O’Moore, R.; Coakley, D.; Walsh, J.B. Vitamin D-fortified liquid milk: Benefits for the elderly community-based population. Calcif. Tissue Int. 1998, 62, 300-302. [CrossRef] [PubMed]

21. Daly, R.M.; Brown, M.; Bass, S.; Kukuljan, S.; Nowson, C. Calcium- and vitamin D3-fortified milk reduces bone loss at clinically relevant skeletal sites in older men: A 2-year randomized controlled trial. J. Bone Miner. Res. 2006, 21, 397-405. [CrossRef] [PubMed]

22. Kukuljan, S.; Nowson, C.; Bass, S.; Sanders, K.; Nicholson, G.C.; Seibel, M.J.; Salmon, J.; Daly, R.M. Effects of a multi-component exercise program and calcium-vitamin-D3-fortified milk on bone mineral density in older men: A randomised controlled trial. Osteoporos. Int. 2009, 20, 1241-1251. [CrossRef] [PubMed]

23. Nikooyeh, B.; Neyestani, T.R.; Farvid, M.; Alavi-Majd, H.; Houshiarrad, A.; Kalayi, A.; Shariatzadeh, N.; Gharavi, A.; Heravifard, S.; Tayebinejad, N.; et al. Daily consumption of vitamin D- or vitamin D + calcium-fortified yogurt drink improved glycemic control in patients with type 2 diabetes: A randomized clinical trial. Am. J. Clin. Nutr. 2011, 93, 764-771. [CrossRef] [PubMed]

24. Shab-Bidar, S.; Neyestani, T.R.; Djazayery, A.; Eshraghian, M.R.; Houshiarrad, A.; Gharavi, A.; Kalayi, A.; Shariatzadeh, N.; Zahedirad, M.; Khalaji, N.; et al. Regular consumption of vitamin D-fortified yogurt drink (Doogh) improved endothelial biomarkers in subjects with type 2 diabetes: A randomized double-blind clinical trial. BMC Med. 2011, 9, 125. [CrossRef] [PubMed]

25. Jääskeläinen, T.; Itkonen, S.T.; Lundqvist, A.; Erkkola, M.; Koskela, T.; Lakkala, K.; Dowling, K.G.; Hull, G.; Kröger, H.; Karppinen, J.; et al. The positive impact of general food fortification policy on vitamin D status in a representative adult Finnish population: Evidence from an 11-year follow-up based on standardized 25-hydroxyvitamin D. data. Am. J. Clin. Nutr. 2017, 105, 1512-1520. [CrossRef] [PubMed]

26. Institute of Medicine Food and Nutrition Board. Dietary Reference Intakes for Adequacy: Calcium and Vitamin D; The National Academies Press: Washington, DC, USA, 2011.

27. Holm Totland, T.; Kjerpeseth Melnaes, B.; Lundberg-Hallén, N.; Helland-Kigen, K.M.; Lund-Blix, N.A.; Borch Myhre, J.; Wetting Johansen, A.M.; Bjørge Løken, E.; Frost Andersen, L. A representative Study on Nutrient Intakes among 18-70 Year-Old Men and Women in Norway). Available online: https: / helsedirektoratet.no/Lists / Publikasjoner/Attachments/301/Norkost-3-en-landsomfattendekostholdsundersokelse-blant-menn-og-kvinner-i-norge-i-alderen-18-70-ar-2010-11-IS-2000.pdf (accessed on 1 June 2018).

28. Amcoff, E.; Edberg, A.; Enghardt Barbieri, H.; Lindroos, A.K.; Nälsén, C.; Pearson, M.; Warensjö Lemming, E. Livsmedels-och näringsintag bland vuxna i Sverige. Available online: https://www.livsmedelsverket. se/globalassets/publikationsdatabas/rapporter/2011/riksmaten_2010_20111.pdf?id=3588 (accessed on 1 June 2018).

29. Cole, C.R.; Grant, F.K.; Tangpricha, V.; Swaby-Ellis, E.D.; Smith, J.L.; Jacques, A.; Chen, H.; Schleicher, R.L.; Ziegler, T.R. 25-hydroxyvitamin D status of healthy, low-income, minority children in Atlanta, Georgia. Pediatrics 2010, 125, 633-639. [CrossRef] [PubMed]

30. Mark, S.; Lambert, M.; Delvin, E.E.; O’Loughlin, J.; Tremblay, A.; Gray-Donald, K. Higher vitamin D intake is needed to achieve serum 25(OH)D levels greater than $50 \mathrm{nmol} / \mathrm{L}$ in Québec youth at high risk of obesity. Eur J. Clin Nutr 2011, 65, 486-492. [CrossRef] [PubMed]

31. Soininen, S.; Eloranta, A.M.; Lindi, V.; Venäläinen, T.; Zaproudina, N.; Mahonen, A.; Lakka, T.A. Determinants of serum 25-hydroxyvitamin D concentration in Finnish children: The Physical Activity and Nutrition in Children (PANIC) study. Br. J. Nutr. 2016, 115, 1080-1091. [CrossRef] [PubMed]

32. Piirainen, T.; Laitinen, K.; Isolauri, E. Impact of national fortification of fluid milks and margarines with vitamin D on dietary intake and serum 25 -hydroxyvitamin D concentration in 4-year-old children. Eur. J. Clin. Nutr. 2007, 61, 123-128. [CrossRef] [PubMed]

33. Poliquin, S.; Joseph, L.; Gray-Donald, K. Calcium and vitamin D intakes in an adult Canadian population. Can. J. Diet. Pract. Res. 2009, 70, 21-27. [CrossRef] [PubMed]

34. Moore, C.; Murphy, M.M.; Keast, D.R.; Holick, M.F. Vitamin D intake in the United States. J. Am. Diet. Assoc. 2004, 104, 980-983. [CrossRef] [PubMed] 
35. Vatanparast, H.; Calvo, M.S.; Green, T.J.; Whiting, S.J. Despite mandatory fortification of staple foods, vitamin D intakes of Canadian children and adults are inadequate. J. Steroid. Biochem. Mol. Biol. 2010, 121, 301-303. [CrossRef] [PubMed]

36. Hill, K.M.; Jonnalagadda, S.S.; Albertson, A.M.; Joshi, N.A.; Weaver, C.M. Top food sources contributing to vitamin $\mathrm{D}$ intake and the association of ready-to-eat cereal and breakfast consumption habits to vitamin $\mathrm{D}$ intake in Canadians and United States Americans. J. Food. Sci. 2012, 77, H170-175. [CrossRef] [PubMed]

37. Moore, C.E.; Radcliffe, J.D.; Liu, Y. Vitamin D intakes of adults differ by income, gender and race/ethnicity in the USA, 2007 to 2010. Public Health Nutr. 2014, 17, 756-763. [CrossRef] [PubMed]

38. Kolahdooz, F.; Barr, A.; Roache, C.; Sheehy, T.; Corriveau, A.; Sharma, S. Dietary adequacy of vitamin D and calcium among Inuit and Inuvialuit women of child-bearing age in Arctic Canada: A growing concern. PLoS ONE 2013, 8, e78987. [CrossRef] [PubMed]

39. Levy, M.A.; McKinnon, T.; Barker, T.; Dern, A.; Helland, T.; Robertson, J.; Cuomo, J.; Wood, T.; Dixon, B.M. Predictors of vitamin D status in subjects that consume a vitamin D supplement. Eur. J. Clin. Nutr. 2015, 69, 84-89. [CrossRef] [PubMed]

40. O’Dowd, K.J.; Clemens, T.L.; Kelsey, J.L.; Lindsay, R. Exogenous calciferol (vitamin D) and vitamin D endocrine status among elderly nursing home residents in the New York City area. J. Am. Geriatr. Soc. 1993, 41, 414-421. [CrossRef] [PubMed]

41. Kinyamu, H.K.; Gallagher, J.C.; Rafferty, K.A.; Balhorn, K.E. Dietary calcium and vitamin D intake in elderly women: Effect on serum parathyroid hormone and vitamin D. metabolites. Am. J. Clin. Nutr. 1998, 67, 342-348. [CrossRef] [PubMed]

42. Raulio, S.; Erlund, I.; Männistö, S.; Sarlio-Lähteenkorva, S.; Sundvall, J.; Tapanainen, H.; Vartiainen, E.; Virtanen, S.M. Successful nutrition policy: Improvement of vitamin D intake and status in Finnish adults over the last decade. Eur. J. Public Health 2017, 27, 268-273. [CrossRef] [PubMed]

43. Abu Shady, M.M.; Youssef, M.M.; Salah El-Din, E.M.; Abdel Samie, O.M.; Megahed, H.S.; Salem, S.M.; Mohsen, M.A.; Abdel Aziz, A.; El-Toukhy, S. Predictors of serum 25-hydroxyvitamin D concentrations among a sample of Egyptian schoolchildren. Sci. World J. 2016, 2016, 8175768. [CrossRef] [PubMed]

44. Gharaibeh, M.A.; Stoecker, B.J. Assessment of serum 25(OH)D concentration in women of childbearing age and their preschool children in Northern Jordan during summer. Eur. J. Clin. Nutr. 2009, 63, 1320-1326. [CrossRef] [PubMed]

45. Rosendahl, J.; Fogelholm, M.; Pelkonen, A.; Mäkelä, M.J.; Mäkitie, O.; Erkkola, M. A history of cow's milk allergy is associated with lower vitamin D status in schoolchildren. Horm. Res. Paediatr. 2017, 88, 244-250. [CrossRef] [PubMed]

46. Lee, G.J.; Birken, C.S.; Parkin, P.C.; Lebovic, G.; Chen, Y.; L'Abbé, M.R.; Maguire, J.L. TARGet Kids! Collaboration. Consumption of non-cow's milk beverages and serum vitamin D levels in early childhood. CMAJ 2014, 186, 1287-1293. [CrossRef] [PubMed]

47. Munasinghe, L.L.; Yuan, Y.; Willows, N.D.; Faught, E.L.; Ekwaru, J.P.; Veugelers, P.J. Vitamin D deficiency and sufficiency among Canadian children residing at high latitude following the revision of the RDA of vitamin D intake in 2010. Br. J. Nutr. 2017, 117, 457-465. [CrossRef] [PubMed]

48. Munasinghe, L.L.; Yuan, Y.; Willows, N.D.; Faught, E.L.; Ekwaru, J.P.; Veugelers, P.J. Vitamin D deficiency and sufficiency among Canadian children residing at high latitude following the revision of the RDA of vitamin D intake in 2010—CORRIGENDUM. Br. J. Nutr. 2017, 117, 1052-1054. [CrossRef] [PubMed]

49. Rodríguez-Rodríguez, E.; Aparicio, A.; López-Sobaler, A.M.; Ortega, R.M. Vitamin D status in a group of Spanish schoolchildren. Minerva Pediatr. 2011, 63, 11-18. [PubMed]

50. Barman, M.; Jonsson, K.; Hesselmar, B.; Sandin, A.; Sandberg, A.S.; Wold, A.E. No association between allergy and current 25-hydroxy vitamin D in serum or vitamin D intake. Acta Paediatr. 2015, 104, 405-413. [CrossRef] [PubMed]

51. Öberg, J.; Jorde, R.; Almås, B.; Emaus, N.; Grimnes, G. Vitamin D deficiency and lifestyle risk factors in a Norwegian adolescent population. Scand. J. Public Health 2014, 42, 593-602. [CrossRef] [PubMed]

52. Charatcharoenwitthaya, N.; Nanthakomon, T.; Somprasit, C.; Chanthasenanont, A.; Chailurkit, L.O.; Pattaraarchachai, J.; Ongphiphadhanakul, B. Maternal vitamin D status, its associated factors and the course of pregnancy in Thai women. Clin. Endocrinol. (Oxf.) 2013, 78, 126-133. [CrossRef] [PubMed] 
53. Hauta-Alus, H.H.; Holmlund-Suila, E.M.; Rita, H.J.; Enlund-Cerullo, M.; Rosendahl, J.; Valkama, S.M.; Helve, O.M.; Hytinantti, T.K.; Surcel, H.M.; Mäkitie, O.M.; et al. Season, dietary factors, and physical activity modify 25-hydroxyvitamin D concentration during pregnancy. Eur. J. Nutr. 2018, 57, 1369-1379. [CrossRef] [PubMed]

54. Hobbs, R.D.; Habib, Z.; Alromaihi, D.; Idi, L.; Parikh, N.; Blocki, F.; Rao, D.S. Severe vitamin D deficiency in Arab-American women living in Dearborn, Michigan. Endocr. Pract. 2009, 15, 35-40. [CrossRef] [PubMed]

55. Langlois, K.; Greene-Finestone, L.; Little, J.; Hidiroglou, N.; Whiting, S. Vitamin D status of Canadians as measured in the 2007 to 2009 Canadian Health Measures Survey. Health Rep. 2010, 21, 47-55. [PubMed]

56. Burgaz, A.; Akesson, A.; Oster, A.; Michaëlsson, K.; Wolk, A. Associations of diet, supplement use, and ultraviolet B radiation exposure with vitamin D status in Swedish women during winter. Am. J. Clin. Nutr. 2007, 86, 1399-1404. [CrossRef] [PubMed]

57. McCarroll, K.; Beirne, A.; Casey, M.; McNulty, H.; Ward, M.; Hoey, L.; Molloy, A.; Laird, E.; Healy, M.; Strain, J.J.; et al. Determinants of 25-hydroxyvitamin D in older Irish adults. Age Ageing 2015, 44, 847-853. [CrossRef] [PubMed]

58. Carter, G.D. 25-hydroxyvitamin D: A difficult analyte. Clin. Chem. 2012, 58, 486-488. [CrossRef] [PubMed]

59. Binkley, N.; Carter, G.D. Toward clarity in clinical vitamin D status assessment: 25(OH)D assay standardization. Endocrinol. Metab. Clin. N. Am. 2017, 46, 885-899. [CrossRef] [PubMed]

60. Harika, R.K.; Dötsch-Klerk, M.; Zock, P.L.; Eilander, A. Compliance with Dietary Guidelines and Increased Fortification Can Double Vitamin D Intake: A. Simulation Study. Ann. Nutr. Metab. 2016, 69, $246-255$. [CrossRef] [PubMed]

61. Allen, R.E.; Dangour, A.D.; Tedstone, A.E.; Chalabi, Z. Does fortification of staple foods improve vitamin D intakes and status of groups at risk of deficiency? A United Kingdom modeling study. Am. J. Clin. Nutr. 2015, 102, 338-344. [CrossRef] [PubMed]

62. Brown, J.; Sandmann, A.; Ignatius, A.; Amling, M.; Barvencik, F. New perspectives on vitamin D food fortification based on a modeling of 25(OH)D concentrations. Nutr. J. 2013, 12, 151. [CrossRef] [PubMed]

63. Kehoe, L.; Walton, J.; McNulty, B.A.; Nugent, A.P.; Flynn, A. Dietary strategies for achieving adequate vitamin D and iron intakes in young children in Ireland. J. Hum. Nutr. Diet. 2017, 30, 405-416. [CrossRef] [PubMed]

(C) 2018 by the authors. Licensee MDPI, Basel, Switzerland. This article is an open access article distributed under the terms and conditions of the Creative Commons Attribution (CC BY) license (http://creativecommons.org/licenses/by/4.0/). 